\title{
Test of Assumption of Equal Variances Using STATCAL (R), SPSS \& Minitab
}
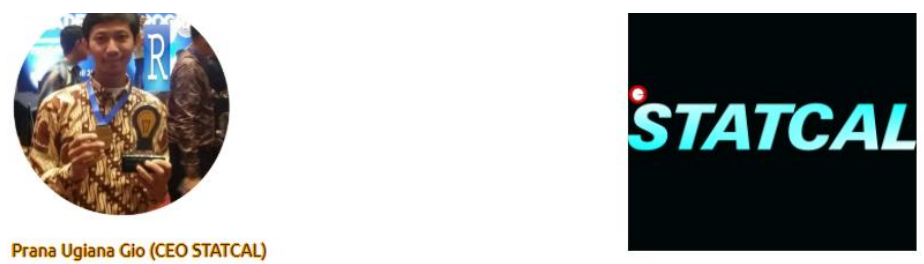

Created by Prana Ugiana Gio \& Rezzy Eko Caraka

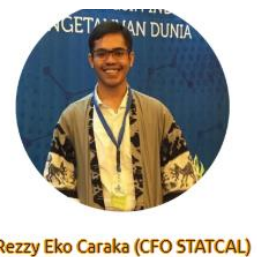

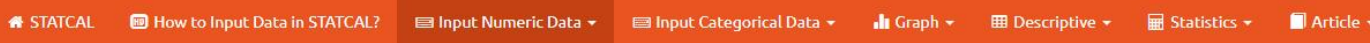

Numeric Data

\begin{tabular}{|c|c|c|c|c|c|c|c|c|c|c|c|c|c|c|c|c|c|c|c|}
\hline Nanne of Varisble & \multicolumn{19}{|c|}{ Selt Number of Colunno } \\
\hline Score A & \multirow{2}{*}{\multicolumn{19}{|c|}{$\begin{array}{l}\text { Set Number of Row } \\
11\end{array}$}} \\
\hline Score B & & & & & & & & & & & & & & & & & & & \\
\hline \multirow[t]{3}{*}{ Score C } & & $\mathrm{v} 1$ & v2 & V3 & $\mathrm{V} 4$ & V5 & V6 & V7 & v8 & v9 & V10 & V11 & $\mathrm{V} 12$ & $\mathrm{~V} 13$ & V14 & V15 & V16 & V17 & V18 \\
\hline & 1 & 78.00 & 75.00 & 75.00 & & & & & & & & & & & & & & & \\
\hline & 2 & 75.00 & 98.00 & 57.00 & & & & & & & & & & & & & & & \\
\hline
\end{tabular}

By: Prana Ugiana Gio \& Rezzy Eko Caraka

\section{Download STATCAL in www.statcal.com}

\section{Citations}

\section{APA}

Gio, P. U., \& Caraka, R. E. (2019, January 24). Test of Assumption of Equal Variances Using STATCAL (R), SPSS and Minitab. Retrieved from osf.io/preprints/inarxiv/68a3p

MLA

Gio, Prana U., and Rezzy E. Caraka. "Test of Assumption of Equal Variances Using STATCAL (R), SPSS and Minitab." INA-Rxiv, 24 Jan. 2019. Web.

\section{Chicago}

Gio, Prana U., and Rezzy E. Caraka. 2019. "Test of Assumption of Equal Variances Using STATCAL (R), SPSS and Minitab." INA-Rxiv. January 24. osf.io/preprints/inarxiv/68a3p. 


\section{CONTENT}

1.1 Data

1.2 Input Numeric Data in STATCAL

1.3 Input Categorical Data in STATCAL

1.4 Test of Assumption of Equal Variances with STATCAL

1.5 STATCAL's Result

1.6 Comparison with SPSS

1.7 Comparison with Minitab 
In this article, we will explain step by step how to test of assumption of equal variances using STATCAL. Beside that, we will compare STATCAL's result with other software such as SPSS \& Minitab.

\subsection{Data}

Table 1.1.1 is presented data of 17 persons of score A based on group A, B and C.

Table 1.1.1

\begin{tabular}{|c|c|c|}
\hline Person & Group & Score A \\
\hline 1 & 1 & 54 \\
\hline 2 & 1 & 57 \\
\hline 3 & 1 & 53 \\
\hline 4 & 1 & 52 \\
\hline 5 & 1 & 49 \\
\hline 6 & 1 & 48 \\
\hline 7 & 2 & 67 \\
\hline 8 & 2 & 68 \\
\hline 9 & 2 & 65 \\
\hline 10 & 2 & 67 \\
\hline 11 & 2 & 65 \\
\hline 12 & 3 & 87 \\
\hline 13 & 3 & 86 \\
\hline 14 & 3 & 81 \\
\hline 15 & 3 & 93 \\
\hline 16 & 3 & 87 \\
\hline 17 & 3 & 88 \\
\hline
\end{tabular}

\begin{tabular}{|c|c|}
\hline Value & Label for Group \\
\hline 1 & Group A \\
\hline 2 & Group B \\
\hline 3 & Group C \\
\hline
\end{tabular}

Based on the data in Table 1.1.1, we will test assumption of equal variances of score A based on group A, B and C using STATCAL. 


\subsection{Input Numeric Data in STATCAL}

Input numeric data in STATCAL as in Figure 1.2.1 until Figure 1.2.3.

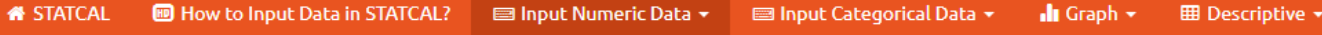

\section{Numeric Data}

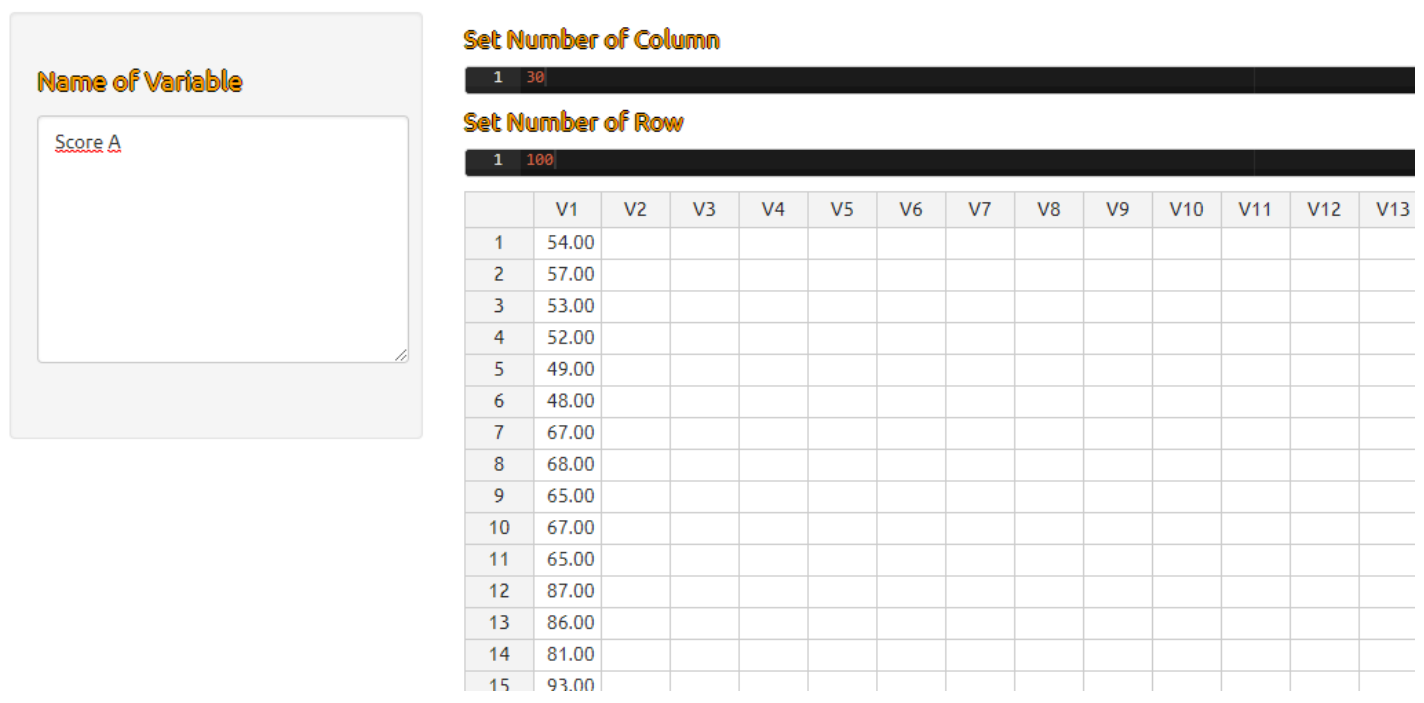

Figure 1.2.1 Input Numeric Data

\begin{tabular}{|c|c|c|}
\hline * STATCAL & 䧃 How to Input Data in STATCAL? & 国 Input Numeric Data . \\
\hline & & 国 Input Numeric Data \\
\hline
\end{tabular}

\begin{tabular}{|c|c|c|c|c|c|c|}
\hline & \multirow{2}{*}{\multicolumn{4}{|c|}{ 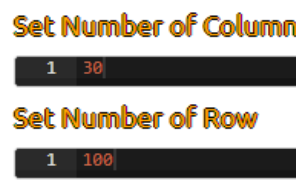 }} & & \\
\hline \multirow{14}{*}{ Score A } & & & & & & \\
\hline & & V1 & V2 & V3 & V4 & v5 \\
\hline & 1 & 54.00 & & & & \\
\hline & 2 & 57.00 & & & & \\
\hline & 3 & 53.00 & & & & \\
\hline & 4 & 52.00 & & & & \\
\hline & 5 & 49.00 & & & & \\
\hline & 6 & 48.00 & & & & \\
\hline & 7 & 67.00 & & & & \\
\hline & 8 & 68.00 & & & & \\
\hline & 9 & 65.00 & & & & \\
\hline & 10 & 67.00 & & & & \\
\hline & 11 & 65.00 & & & & \\
\hline & 12 & 87.00 & & & & \\
\hline
\end{tabular}

Figure 1.2.2 Giving Name of Variable 


\section{Your Numeric Data}

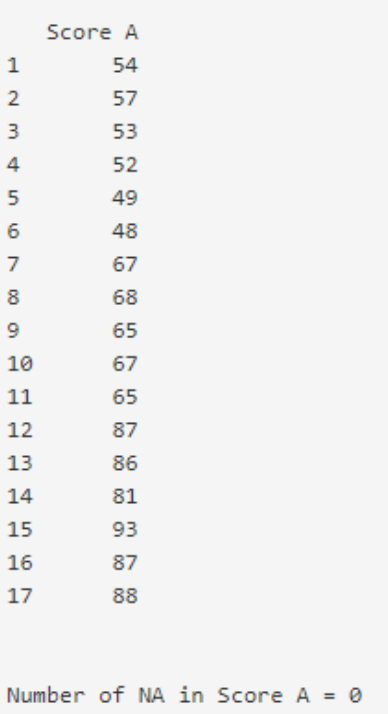

Figure 1.2.3 Your Numeric Data Must be Appeared in "Your Numeric Data" Part

\subsection{Input Categorical Data in STATCAL}

Input categorical data in STATCAL as in Figure 1.3.1 until Figure 1.3.3.

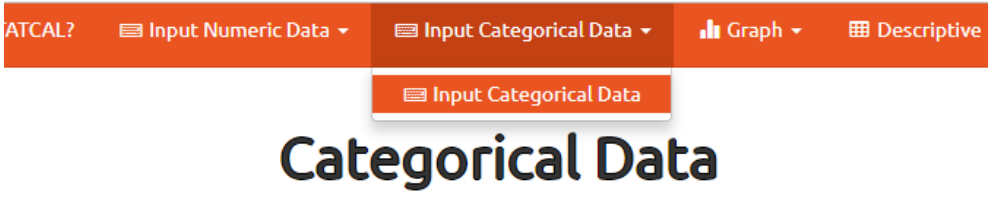

Sett Number of Coluñก

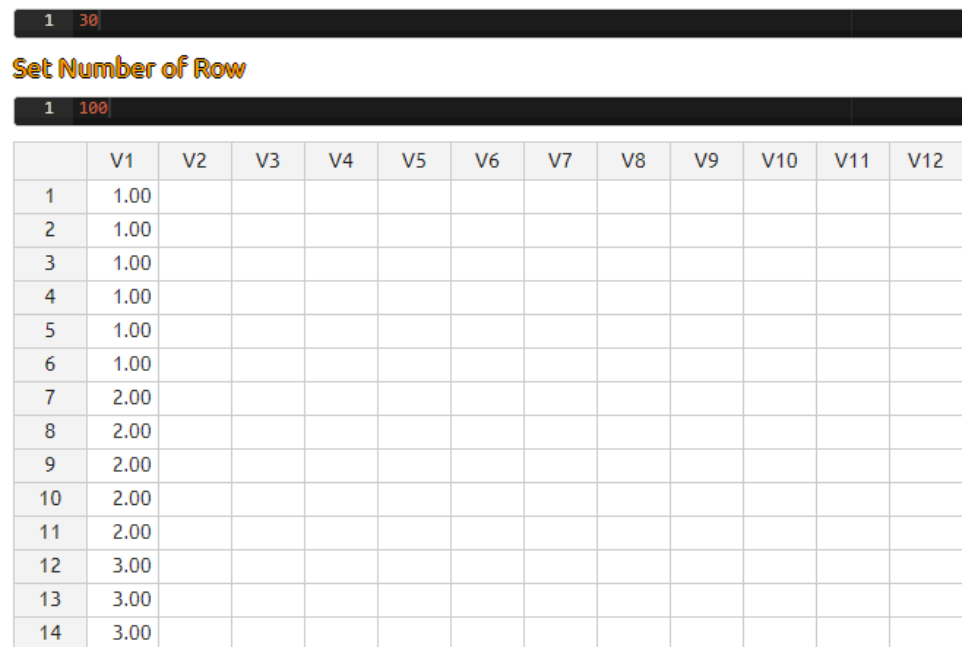

Figure 1.3.1 Input Categorical Data 


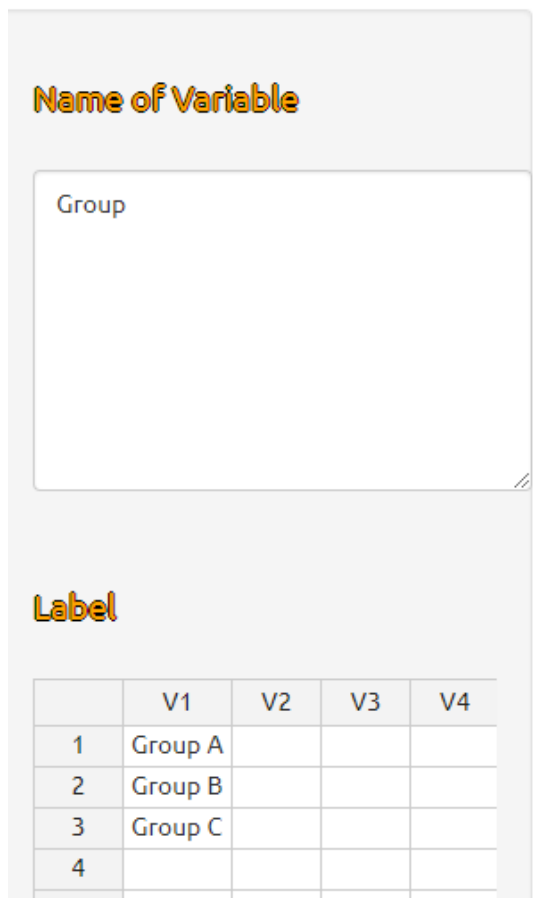

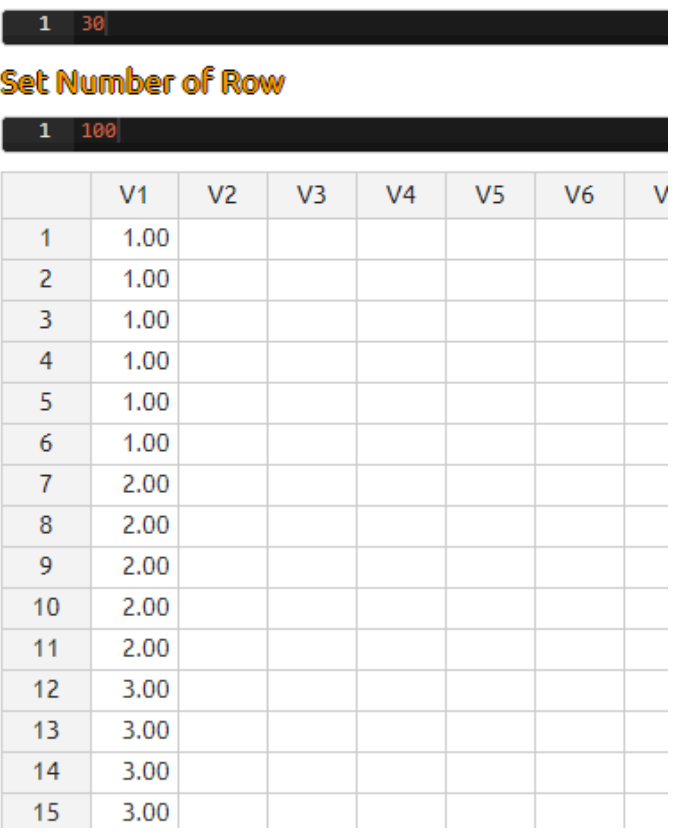

Figure 1.2.2 Giving Name and Label

\section{Your Categorical Data}

Figure 1.3.3 Your Categorical Data Must be Appeared in "Your Categorical Data" Part 


\subsection{Test of Assumption of Equal Variances with STATCAL}

For testing assumption of equal variances in STATCAL, choose Statistics $\Rightarrow$ Test of Homogeneity of Variance (Figure 1.4.1). In Figure 1.4.2, variable Score A and Group are moved to the right box.

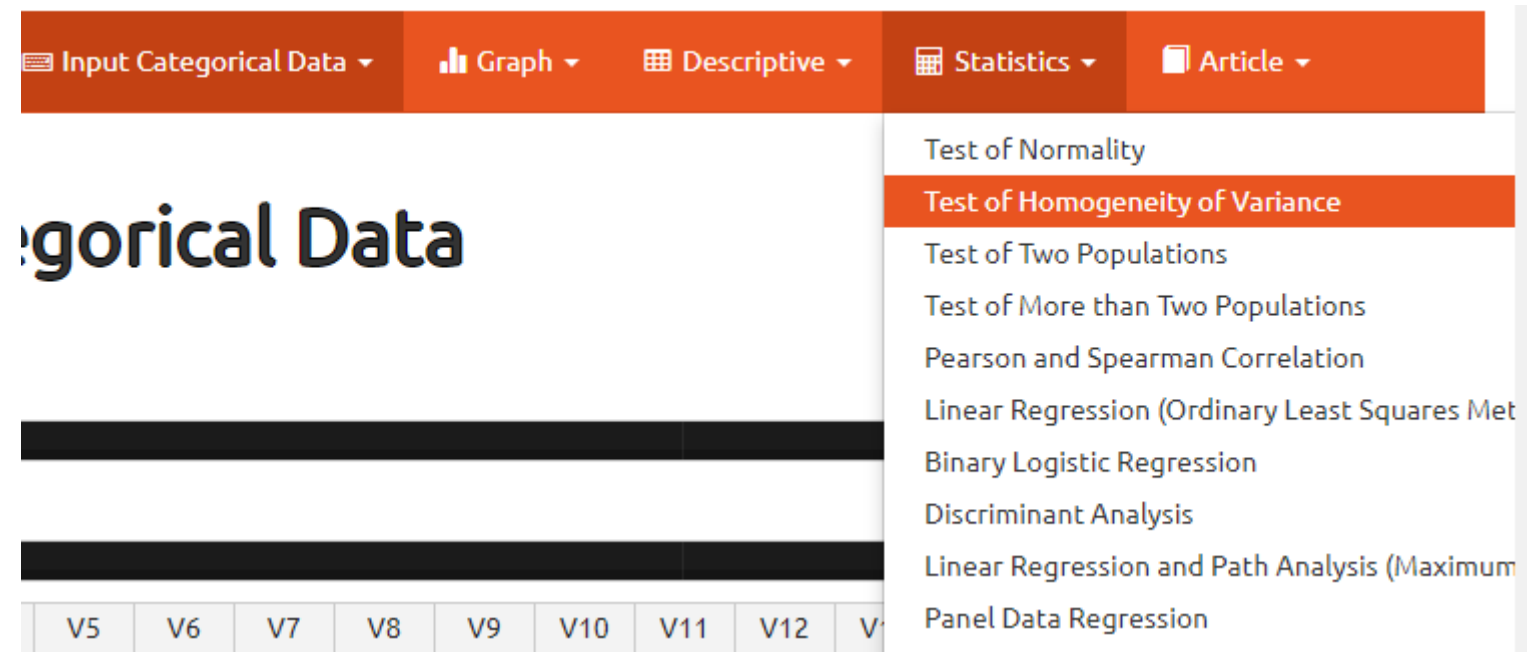

Figure 1.4.1 Menu for Testing Assumption of Equal Variances in STATCAL

\section{Test of Homogeneity of Variance (Assumption)}

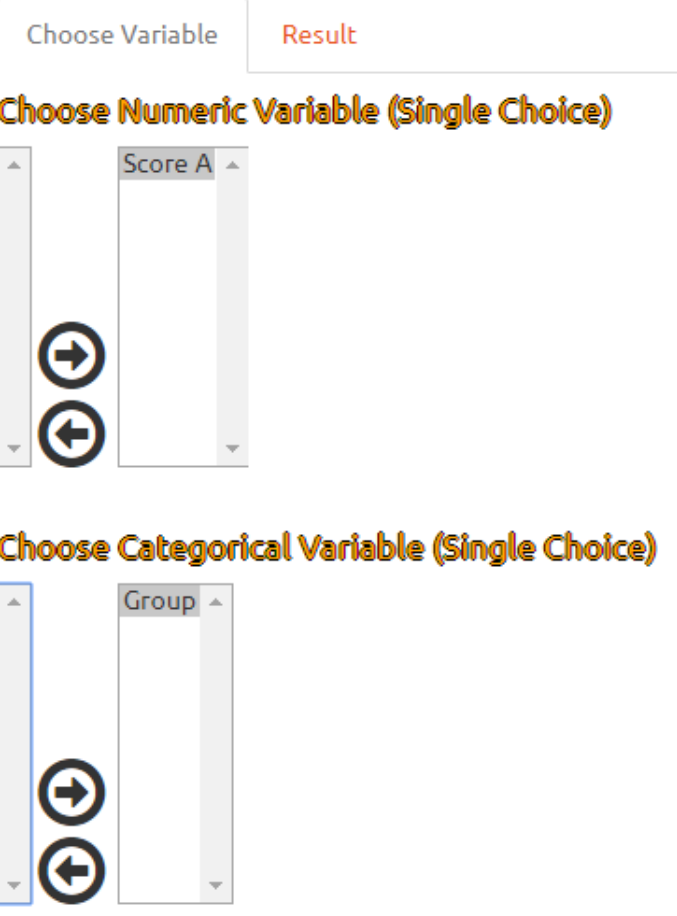

Figure 1.4.2 Selection of Variable 


\subsection{STATCAL's Result}

Result of STATCAL can be seen in Result part.

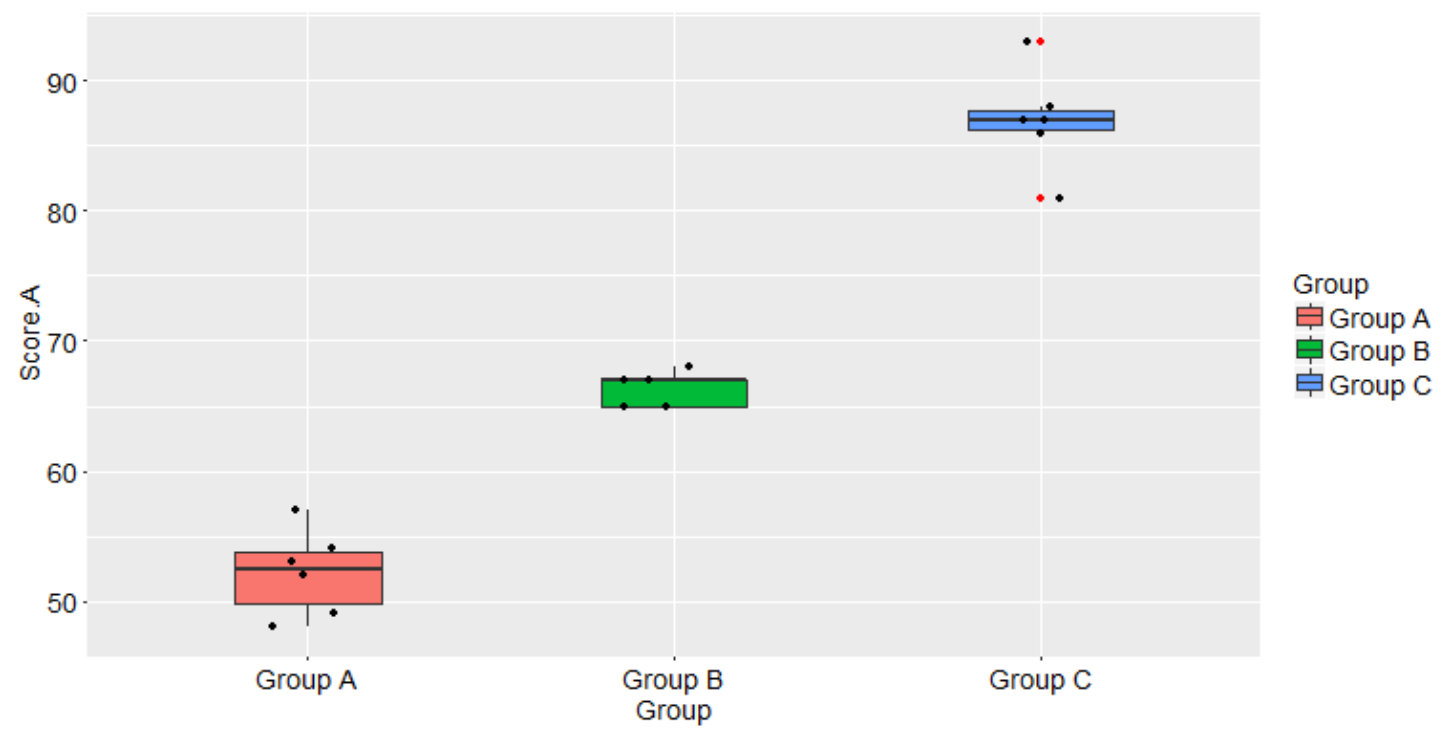

Figure 1.5.1 Boxplot

\section{Levene Test}

\begin{tabular}{|c|c|c|c|c|}
\hline Show 10 & V entr & & & Search: \\
\hline$d f 1 \triangleq$ & $d f 2 \Rightarrow$ & $\begin{array}{l}\text { statistic of } \\
\text { levene }\end{array}$ & $\begin{array}{c}\mathrm{p}- \\
\text { value }\end{array}$ & conclusion \\
\hline 2 & 14 & 0.7068 & 0.51 & $\begin{array}{l}\mathrm{p} \text {-value }>0.05 \text {, assumption of homogeneity of variance is received, at } \\
\text { the level of significance is } 5 \%\end{array}$ \\
\hline
\end{tabular}

Figure 1.5.2 Test of Assumption of Equal Variances Using Levene Test

\section{Bartlett Test}

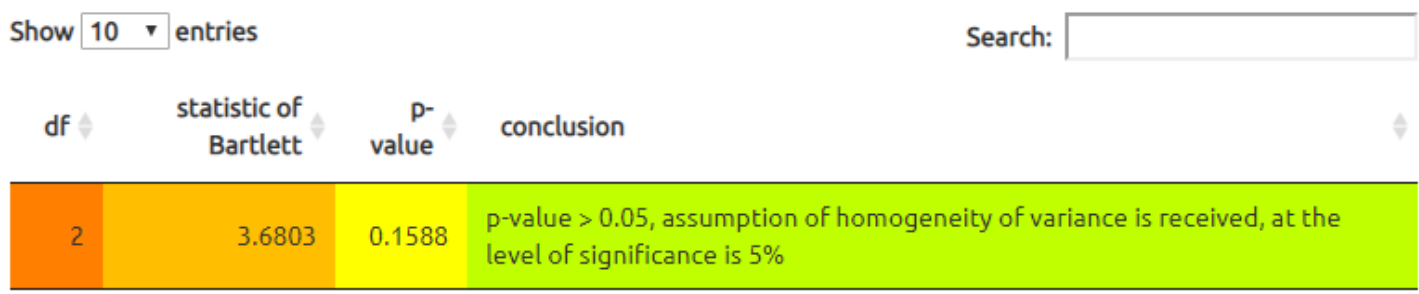

Figure 1.5.3 Test of Assumption of Equal Variances Using Bartlett Test 


\section{Test of Normality (Assumption) with Kolmogorov- Smirnov}

\begin{tabular}{|c|c|c|c|c|}
\hline Show 10 & - entries & & Sear & \\
\hline Group & $\Rightarrow$ & Statistic of Kolomogorov-Smirnov (KS) $=$ & P-Value of $\mathrm{KS}=$ & Number of Observation \\
\hline Group A & & 0.164 & 0.997 & 6 \\
\hline Group B & & 0.273 & 0.851 & 5 \\
\hline Group C & & 0.231 & 0.907 & 6 \\
\hline
\end{tabular}

Figure 1.5.4 Normality Assumption Test Result Based on Kolmogorov-Smirnov Test

\subsection{Comparison with SPSS}

Given SPSS's result for testing assumption of equal variances based on Levene test. We use SPSS version 17.

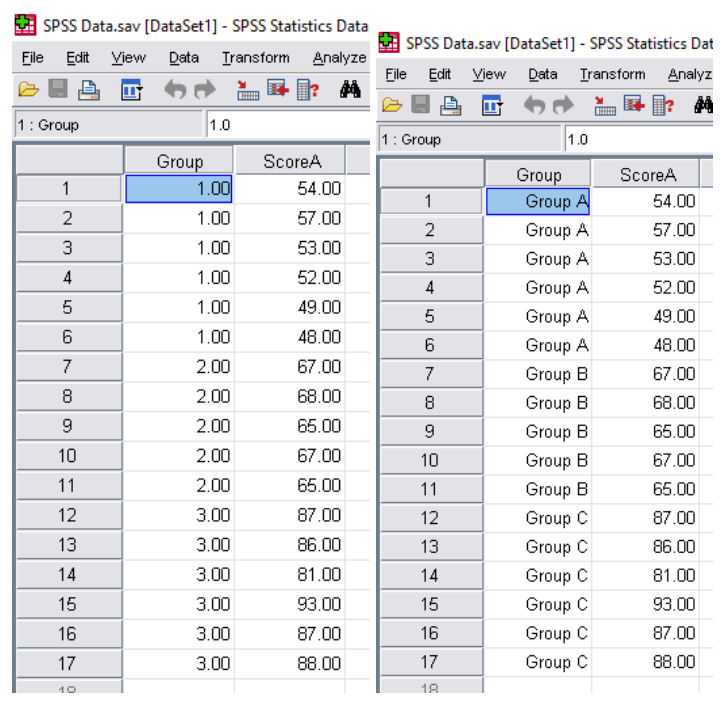

Figure 1.6.1 Data in SPSS

Test of Homogeneity of Variances

Score A

\begin{tabular}{|r|r|r|c|}
\hline $\begin{array}{c}\text { Levene } \\
\text { Statistic }\end{array}$ & df1 & \multicolumn{1}{c|}{$\mathrm{df2}$} & Sig. \\
\hline .707 & 2 & 14 & .510 \\
\hline
\end{tabular}

Figure 1.6.2 Result of Levene Test Based on SPSS 


\subsection{Comparison with Minitab}

Given Minitab's result for testing assumption of equal variances. We use Minitab version 16.

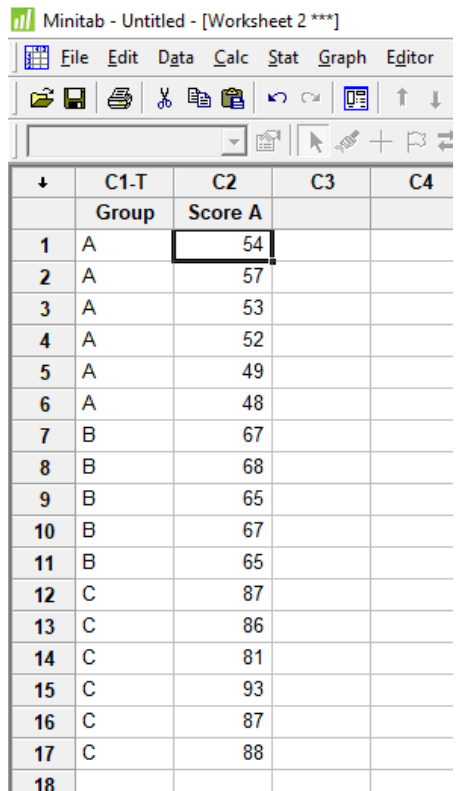

\begin{tabular}{|l|l|l|l|l}
\hline Stat Graph Editor Iools Window Help Assistant \\
\hline Basic Statistics \\
Regression
\end{tabular}

Figure 1.8.1 Data in Minitab

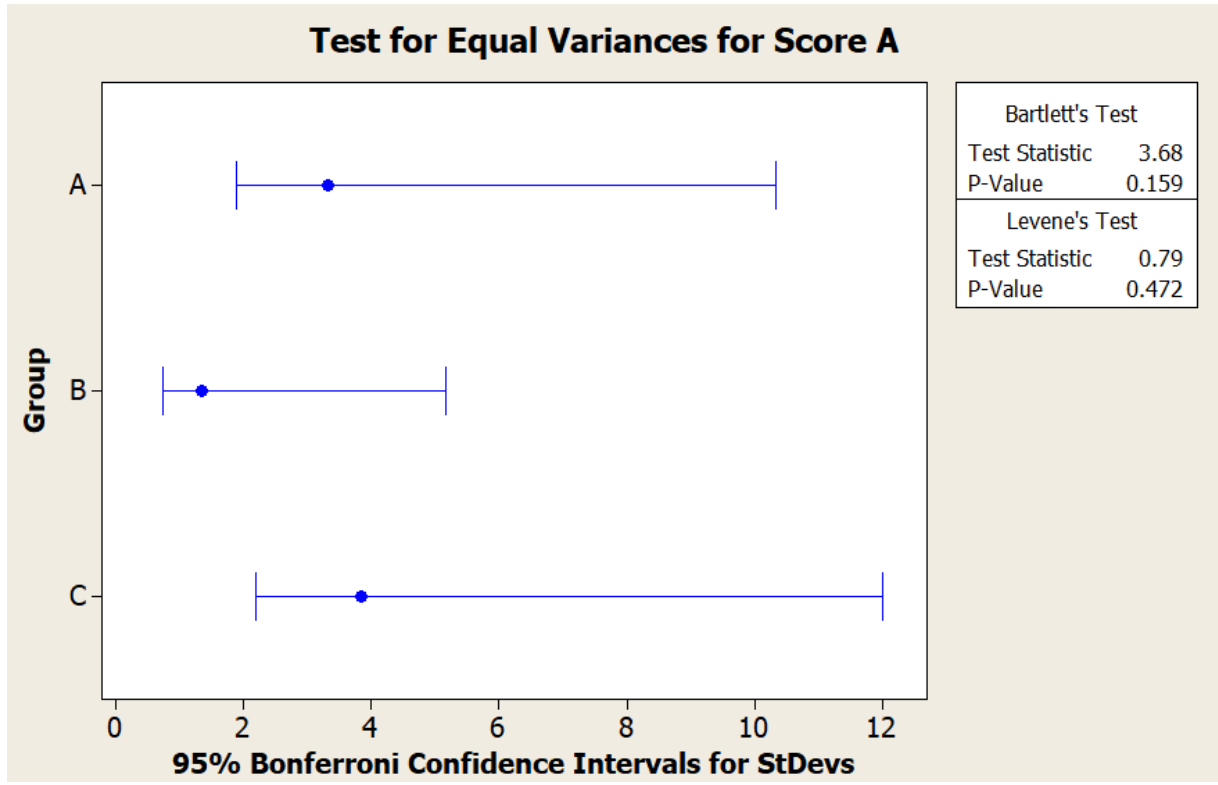

Figure 1.8.2 Result of Levene and Bartlett Test Based on Minitab 